\title{
Self-introduced intravesical magnets in a 3-year-old boy: Case report
}

\author{
Tunç Özdemir, Gizem Orhan, Belce Candan, Gökhan Köylüoğlu \\ Department of Pediatric Surgery, University of Medical Sciences, Tepecik Training and Research Hospital, Yenişehir, İzmir, \\ Turkey.E-mail: ozdemirtunc@yahoo.com \\ Received: 27th December 2017, Revised: 5th April 2018, Accepted: 15th April 2018
}

SUMMARY: Özdemir T, Orhan G, Candan B, Köylüoğlu G. Self-introduced intravesical magnets in a 3-year-old boy: Case report. Turk J Pediatr 2019; 61: 286-288.

Self-introduced intravesical foreign bodies are commonly seen in adults and are rarely encountered in children. The underlying cause may be a psychiatric disorder for sexual gratification or inquisitiveness as in children.

We herein report a 3-year-old boy who was presented with pathological lower urinary tract symptoms and a radiopaque, irregular shaped object in bladder detected by direct abdominal radiograph. Preoperative diagnosis was bladder calculus. Cystolithotomy was planned via Pfannenstiel approach. During operation, self-introduced small magnets and a metallic bead which stuck together were detected.

Intravesical foreign bodies are important considerations in the differential diagnosis of pathological lower urinary tract symptoms. In this case, magnets that were stuck together and a metallic bead mimicked bladder calculus radiologically. However, irregular shape of the intravesical object may arouse a suspicion about the nature.

Key words: bladder, foreign bodies.

Intravesical or intraurethral foreign bodies usually result from iatrogenic injuries, selfintroduction, sexual abuse, assault and rarely migration from adjacent sites. Especially in older patients, presentation may be delayed because of fear of being shamed. Urinary tract infection, pain, voiding difficulties and and haematuria are the usual leading complaints 1,2 . Intravesical foreign bodies are considered to be relatively rare in children. Here we report a 3-year-old boy who self-introduced three small magnets and a metallic bead intravesicularly which stuck together and was confused with bladder calculus.

\section{Case Report}

A three-years-old circumcised boy was admitted with pathological lower urinary tract symptoms of intermittent hematuria and dysuria. Physical examination of the patient including penile meatus was quite normal. A direct supine abdominal X-ray revealed an irregular shaped radioopaque intravesical foreign body (Fig. 1). No abnormalities of the haematological and clinical chemistry laboratory parameters was detected. The urinary sediment showed $>10$ white blood cells/ $\mu \mathrm{L}$ and $30-80$ red blood cells/ $\mu \mathrm{L}$. Abdominal ultrasonography revealed a 3-4 $\mathrm{mm}$ stone formation in right kidney and 2.5 $\mathrm{cm}$ stone formation in bladder.

Because of the size of the "stone" open cystolihtotomy was planned in order to extract the intravesical stone via Pfannenstiel incision. During operation, a gray-black irregular shaped object was seen in bladder. During the attempt to grab the object via hemostat forceps, the object stuck to the forceps. After removal, it was seen that the object was three small spheric magnets and a metallic beam which were stuck together (Fig. 2).

Postoperative course of the patient was uneventful. The patient was evaluated by pediatric psychiatry, postoperatively. Psychiatric pathology was not detected. 


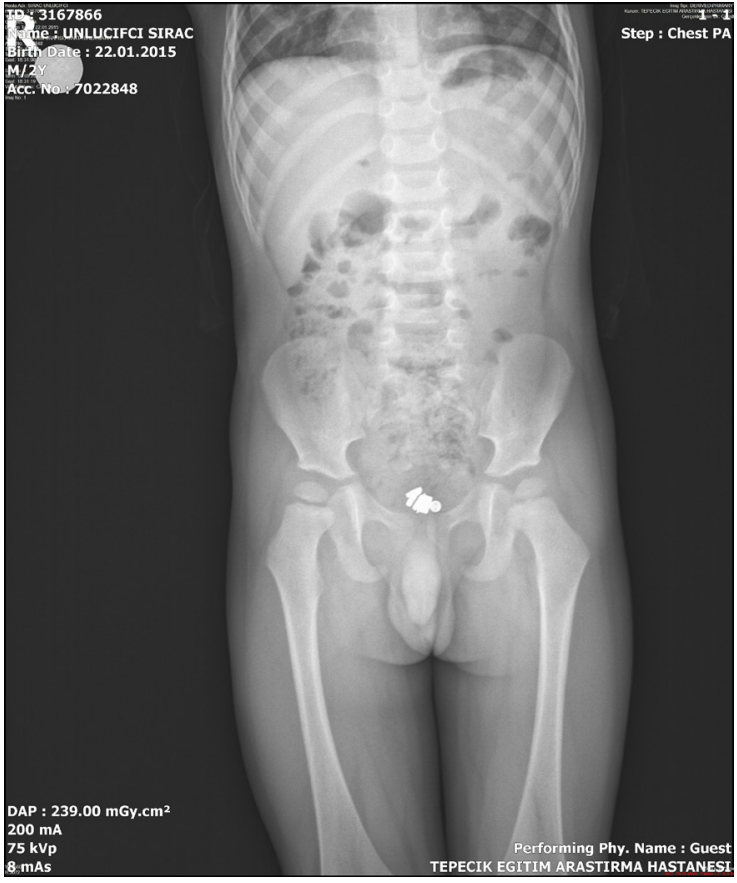

Fig. 1. Irregular shaped radioopaque intravesical foreign body in direct supine abdominal X-ray of the patient.

During the investigation of the medical record of the patient postoperatively, it was detected that, a small spheric radiopaque foreign body was present in a direct abdominal X-ray which was taken for a different purpose one year ago (Fig. 3).

Before preparing this manuscript, informed consent was received from the family.

\section{Discussion}

Self-introduction of foreign bodies in the urinary bladder is not a rare event. A great variety of objects have been found in the lower urinary tract. In adolescents and adults, foreign bodies are mainly introduced for sexual

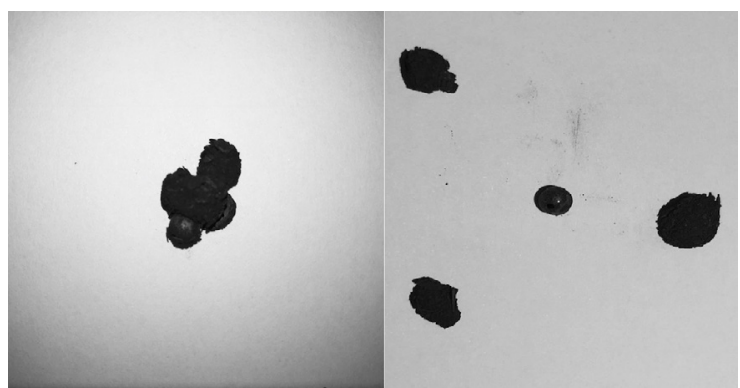

Fig. 2. Removed three small spheric magnets and a metallic beam which were sticking together, and detached from each other after removal.

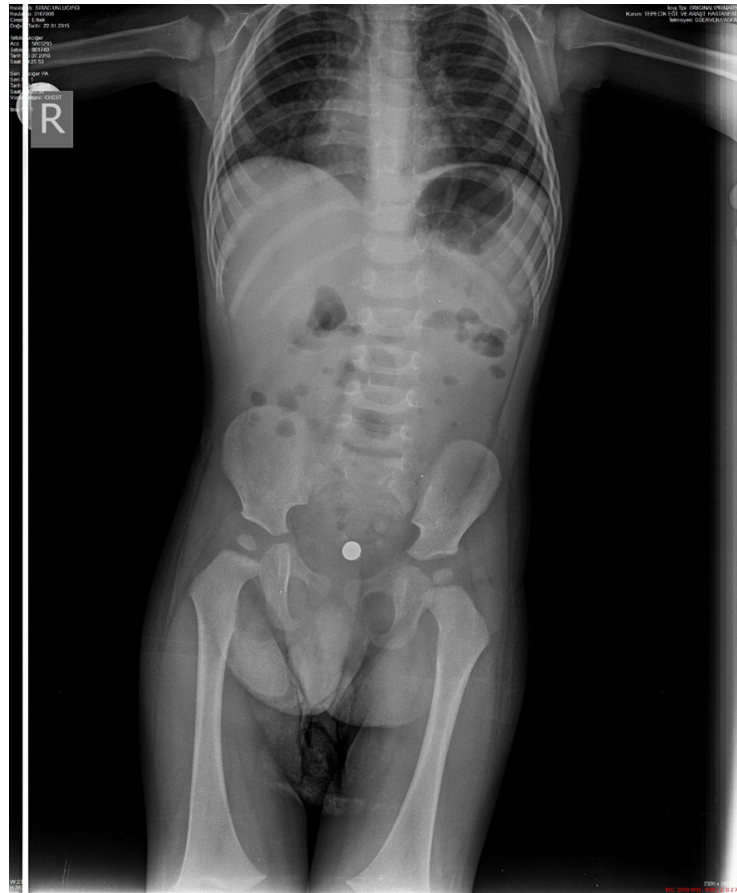

Fig. 3. A small spheric radiopaque foreign body seen on a direct abdominal X-ray which was taken for a different purpose one year ago

purposes. Psychiatric disorders such as schizoid personality disorder, or borderline personality disorder, intoxication, mental confusion may be contributed to self-introduction of foreign bodies into the bladder. ${ }^{3-6}$ However, with recent advances in endoscopic urology, many objects such as catheters, stents, and endoscopic instruments are inserted into the urinary tract of patients receiving medical treatment. This has led to an increase in the incidence of iatrogenic foreign bodies. ${ }^{7}$ Common complaints are, hematuria, pain and urinary tract infection. Serious complications such as complete voiding obstruction, severe hematuria, or abscess formation may also ocur. ${ }^{8}$ The physical examination is usually unremarkable, and routine urine microscopy shows only white and red blood cells. Plain pelvic X-ray graphs may reveal radioopaque foreign body. Pelvic ultrasonography also may describe the intravesical object. ${ }^{7}$

Aim of the treatment should be based on minimizing bladder and urethral trauma. Endoscopic removal of the self-introduced or iatrogenic foreign bodies is possible in a majority of patients. ${ }^{7-9}$ However, the age of the patient can restrict the use of endoscopic equipment. 
In cases where endoscopic management is not possible, open surgery is mandatory. Especially in small children, open surgery is usually the method of choice. ${ }^{7}$

Considering the young age of our patient, the first diagnosis was bladder stone. Hence, open cystolithotomy was planned. After removal of the foreign bodies surgically, the parents of the patient were questioned about possible child abuse or previous attempts to self-insert a foreign body. The parents remembered an attempt of the child to insert a straw into the meatus. Furthermore, considering that the presence of a solitary small foreign body into the bladder in the former abdominal X-ray, the patient must have inserted the magnets into the bladder at at least two years of age.

To our knowledge, this is the youngest patient with self-introduced intravesical foreign body. Lessons learned from this patient were; irregular shape of the intravesical radiopaque foreign body should create suspicion about "diagnosis" of bladder stone and even in smaller patients, self-introduced foreign body must be kept in mind with such clinical and radiologic findings.

\section{REFERENCES}

1. van Ophoven A, deKernion JB. Clinical management of foreign bodies of the genitourinary tract. J Urol 2000; 164: 274-287.

2. Rafique M. Intravesical foreign bodies: review and current management strategies. Urol J 2008; 5: 223231.

3. Sukkarieh T, Smaldone M, Shah B. Multiple foreign bodies in the anterior and posterior urethra. Int Braz J Urol 2004; 30: 219-220.

4. Eckford SD, Persad RA, Brewster SF, Gingell JC. Intravesical foreign bodies: five-year review. $\mathrm{Br} \mathrm{J}$ Urol 1992; 69: 41-45.

5. Rahman NU, Elliott SP, McAninch JW. Self-inflicted male urethral foreign body insertion: endoscopic management and complications. BJU Int 2004; 94: 1051-1053.

6. Costa G, Di Tonno F, Capodieci S, Laurini L, Casagrande $\mathrm{R}$, Lavelli D. Self-introduction of foreign bodies into the urethra: a multidisciplinary problem. Int Urol Nephrol 1993; 25: 77-81.

7. Bansal A, Yadav P, Kumar M, et al. Foreign bodies in the urinary bladder and their management: A singlecentre experience from North India. Int Neurourol J 2016; 20: 260-269.

8. Barzilai M, Cohen I, Stein A. Sonographic detection of a foreign body in the urethra and urinary bladder. Urol Int 2000; 64: 178-180.

9. Fath Elbab TK, Abdelhamid AM, Galal EM, Anwar AZ, Malek MA, Tawfiek ER. Management of intravesical self-inflicted sharp objects in children: 10-year single center experience. J Pediatr Urol 2016; 12: 97.e1-5. 